
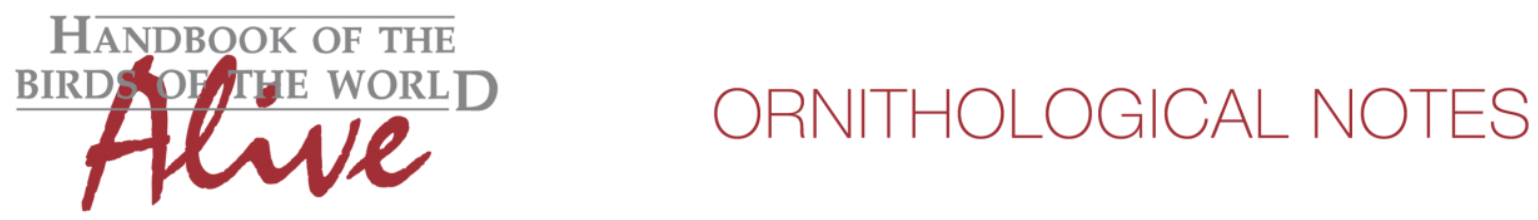

\title{
Notes on the vocalizations of Blackish Antbird (Cercomacra nigrescens)
}

Peter Boesman

In the following we briefly analyze and compare voice of the different races of Blackish Antbird (Cercomacra nigrescens). We also try to quantify the extent of any vocal differences using the criteria proposed by Tobias et al. (2010), as a support for taxonomic review. We have made use of sound recordings available on-line from Xeno Canto (XC).

Loudsong of male in all races is a single lower-pitched note followed by a (usually descending) series of notes. There is however a great variation in pace and note shape (Fig.1).

We have measured a number of basic sound parameters for the six recognized races:

\begin{tabular}{|c|c|c|c|}
\hline & fuscicauda $(n=6)$ & aequatorialis $(n=7)$ & notata $(n=2)$ \\
\hline length first note & $0.145-0.185 \mathrm{~s}$ & $0.12-0.18 \mathrm{~s}$ & $0.12-0.2 \mathrm{~s}$ \\
\hline max. freq. first note & $1950-2300 \mathrm{~Hz}$ & $1700-2000 \mathrm{~Hz}$ & $1900-2000 \mathrm{~Hz}$ \\
\hline max. freq. 2nd note & $2600-3000 \mathrm{~Hz}$ & $2600-3000 \mathrm{~Hz}$ & $2700-2900 \mathrm{~Hz}$ \\
\hline length 2 nd note & $0.016-0.02 \mathrm{~s}$ & $0.085-0.11 \mathrm{~s}$ & $0.07-0.08 \mathrm{~s}$ \\
\hline number of notes & $30-47$ & $6-10$ & $8-13$ \\
\hline length last note & $0.012-0.018 \mathrm{~s}$ & $0.036-0.05 \mathrm{~s}$ & $0.035-0.04 \mathrm{~s}$ \\
\hline max. freq. last note & $1800-2400 \mathrm{~Hz}$ & $2100-2300 \mathrm{~Hz}$ & $2100-2400 \mathrm{~Hz}$ \\
\hline pace* & $0.0165-0.0215$ & $0.09-0.12$ & 0.09 \\
\hline \multirow[t]{2}{*}{ pause between 1 and 2 nd note } & $0.17-0.21 \mathrm{~s}$ & $0.12-0.2 \mathrm{~s}$ & $0.12-0.14 \mathrm{~s}$ \\
\hline & approximans & ochrogyna & nigrescens \\
\hline length first note & $0.12-0.16 \mathrm{~s}$ & $0.14-0.17 \mathrm{~s}$ & $0.13-0.15 \mathrm{~s}$ \\
\hline max. freq. first note & $1900-2150 \mathrm{~Hz}$ & $1700-2100 \mathrm{~Hz}$ & $1550-1700 \mathrm{~Hz}$ \\
\hline max. freq. 2 nd note & $2700-3200 \mathrm{~Hz}$ & $2300-3100 \mathrm{~Hz}$ & $2200-2600 \mathrm{~Hz}$ \\
\hline length 2 nd note & $0.055-0.08 \mathrm{~s}$ & $0.065-0.11 \mathrm{~s}$ & $0.05-0.07 \mathrm{~s}$ \\
\hline \multirow[t]{2}{*}{ number of notes } & $6-13$ & $5-11$ & 14-26 (occasionally \\
\hline & & & incomplete song?) \\
\hline length last note & $0.04-0.045 \mathrm{~s}$ & $0.05-0.07 \mathrm{~s}$ & $0.035-0.04 \mathrm{~s}$ \\
\hline max. freq. last note & $2200-2600 \mathrm{~Hz}$ & $2300-2500 \mathrm{~Hz}$ & $2200-2300 \mathrm{~Hz}$ \\
\hline pace* & $0.075-0.1$ & $0.13-0.23$ & $0.07-0.09$ \\
\hline pause between 1 and 2 nd note & $0.16-0.21 \mathrm{~s}$ & $0.14-0.28 \mathrm{~s}$ & $0.1-0.23 \mathrm{~s}$ \\
\hline
\end{tabular}

("pace expressed here as period, duration between two subsequent notes)

From these measurements, it is clear that fuscicauda has by far the fastest pace (score 3 or 4 ) and number of notes (score 2 or 3), which results in a total score of about 6. 
ochrogyna has clearly the slowest pace (score 2 or 3), note length reduces only slightly resulting in the longest end notes (score 1 or 2). Also, in most cases, every note is preceded by a short artefact note, which if present is quite diagnostic (score 1). Finally, note shape shows a peak when starting. This results in a total score of about 4 vs. all other races.

nigrescens has the largest number of notes after fuscicauda (score 2), has the lowest max. frequencies of the initial note (score 1 or 2). Also, the shape of the notes is quite diagnostic, a sharply descending spiky note (rather than round upslurred such as e.g. aequatorialis). This results in a total score of 3-4 vs. all other races.

The remaining races have smaller differences, which would need more samples to establish any significant difference.
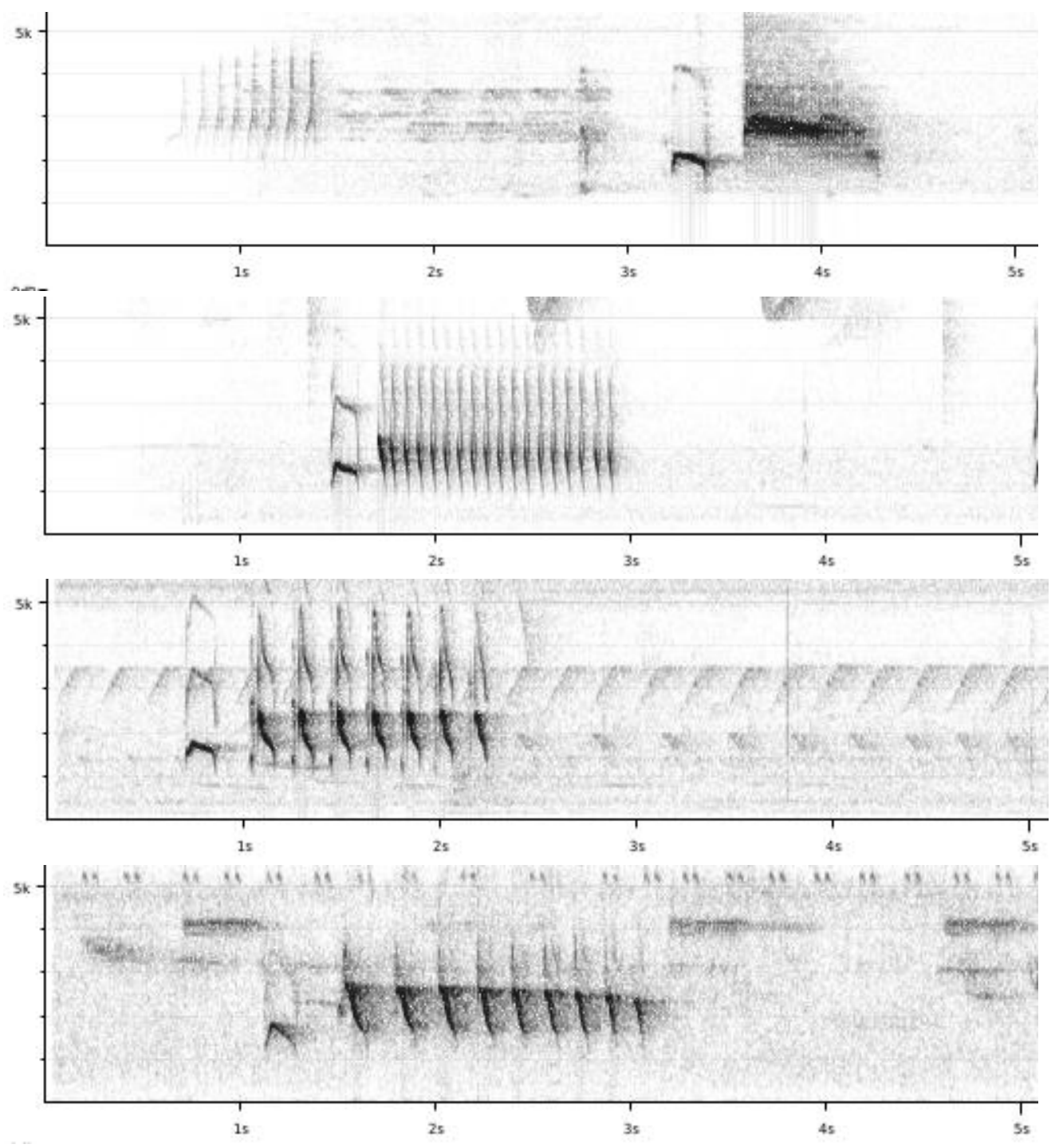

Figure 1: from top to bottom: loudsong of fuscicauda, nigrescens, ochrogyna, aequatorialis 

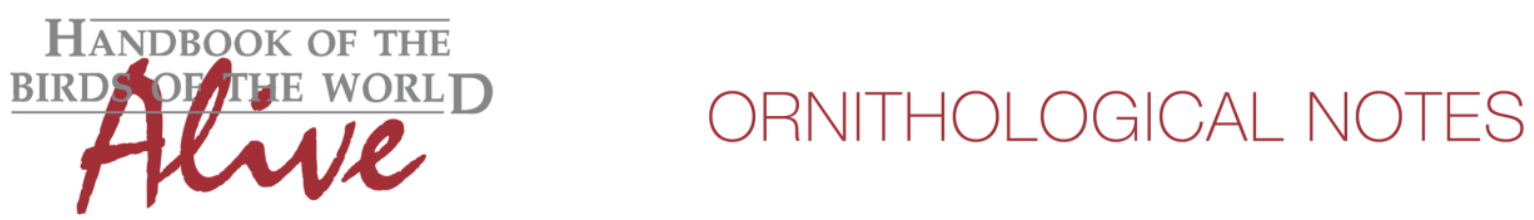

After doing the above analysis, I became aware of a similar published study (Mayer et al. 2014). Data are given for the male loudsong (mean \pm standard deviation), for which effect size can be calculated (only races side by side however, as no grouping was done after defining species limits).

Results are very similar to the above analysis, as can be expected. For example:

aequatorialis vs. fuscicauda

\# notes $\quad 9 \pm 2$ vs $32 \pm 6$-> effect size 5.14 -> score 3

duration $\quad 1.1 \pm 0.3$ vs $0.6 \pm 0.1->$ effect size $2.23->$ score 2

mean pace $\quad 8 \pm 1$ vs $53 \pm 5->$ effect size $12.48->$ score 4

pitch drop $\quad 2.4 \pm 0.8$ vs $6.5 \pm 2.9$-> effect size $1.93->$ score 1

-> total score 7

ochrogyna vs. approximans

duration $\quad 1.5 \pm 0.3$ vs $0.9 \pm 0.3$-> effect size 2 -> score 2 (borderline)

mean pace $\quad 5 \pm 1$ vs $10 \pm 2->$ effect size 3.16 -> score 2

pitch drop $\quad 0.4 \pm 0.4$ vs $2.4 \pm 1.1->$ effect size 2.42 -> score 2

$\rightarrow$ total score 4

nigrescens vs. approximans

highest pitch $\quad 2728 \pm 225$ vs $2275 \pm 144$-> effect size 2.4 -> score 2

(pitch of first note is not given, but is slightly more significant in my measurements)

\# notes $\quad 9 \pm 2$ vs $13 \pm 4$-> effect size 1.26 -> score 1

(number of notes seems to be lower in the samples here -> difference is weaker)

We can thus conclude that the taxon which vocally stands most apart is fuscicauda, having a loudsong which is much faster (score 4) and has higher number of notes (score 2-3).

Races ochrogyna and nigrescens are also moderately differentiated, and each reach a score of about 3-4 vs. all other races.

This note was finalized on 7th May 2015, using sound recordings available on-line at that moment. We would like to thank in particular the many sound recordists who placed their recordings for this species on XC. 


\section{References}

Mayer, S., P. Coopmans, N. Krabbe, and M. L. Isler. 2014. Vocal evidence for species rank to Cercomacra nigrescens fuscicauda J. T. Zimmer. Bulletin British Ornithologists' Club 134: 145-154.

Tobias, J.A., Seddon, N., Spottiswoode, C.N., Pilgrim, J.D., Fishpool, L.D.C. \& Collar, N.J. (2010). Quantitative criteria for species delimitation. Ibis 152(4): 724-746.

\section{Recommended citation}

Boesman, P. (2016). Notes on the vocalizations of Blackish Antbird (Cercomacra nigrescens). HBW Alive Ornithological Note 55. In: Handbook of the Birds of the World Alive. Lynx Edicions, Barcelona. (retrieved from http://www.hbw.com/node/931934 on 30 April 2016). 